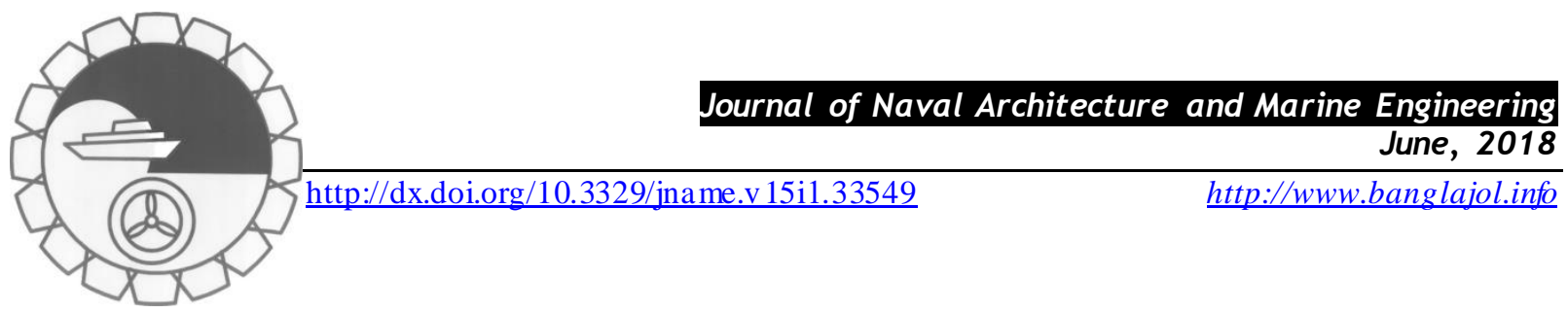

\title{
NATURAL CONVECTIVE FLOW IN CIRCULAR AND ARC CAVITIES FILLED WITH WATER-CU NANOFLUID: A COMPARATIVE STUDY
}

\author{
K. F. U. Ahmed, R. Nasrin* and M. Elias
}

Department of Mathematics, Bangladesh University of Engineering and Technology, Dhaka, Bangladesh *Email: rehena@math.buet.ac.bd

\begin{abstract}
The fluid flow and heat transfer mechanism on steady state solutions obtained in circular and arc-square enclosures filled with water/Cu nanofluid as well as base fluid has been investigated numerically by Galerkin's weighted residual finite element procedure. The left and right boundaries of the cavities are, respectively, heated and cooled at constant temperatures, while their horizontal walls are adiabatic. Effects of buoyancy force (Rayleigh number) and viscous force (Prandtl number) with a wide range of Ra $\left(10^{3}-10^{6}\right)$ and $\operatorname{Pr}(4.2$ - 6.2) on heat transfer phenomenon inside both cavities are observed. The solid volume fraction of water/Cu nanofluid is kept fixed as $2 \%$. The fluid flow and temperature gradient are shown by streamlines and isotherms patterns. From the investigation, it has been reported that the Rayleigh and Prandtl numbers play significant role in heat transfer rate. The variation in heat transfer has been calculated in terms of average Nusselt number. Heat transfer rate has been found to be higher for water/Cu nanofluid with $2 \%$ solid volume fraction than pure water. About $2.7 \%$ higher heat transfer rate has been obtained for circular cavity than that of arc cavity using water/Cu nanofluid at $\mathrm{Ra}=10^{4}$ and $\mathrm{Pr}=5.8$. Better performance of heat transfer mechanism has been observed for circular cavity than arc cavity. It is concluded that using water/Cu nanofluid is advantageous for obtaining higher rate of heat transfer.
\end{abstract}

Keywords: Circular and arc cavities, water/copper nanofluid, natural convection, fluid flow and heat transfer.

\section{NOMENCLATURE}

\begin{tabular}{|c|c|c|c|}
\hline$C_{p}$ & specific heat at constant pressure $\left[\mathrm{Jkg}^{-1} \mathrm{~K}^{-1}\right]$ & $Y$ & $\begin{array}{l}\text { dimensionless distance along } \\
\text { coordinate }\end{array}$ \\
\hline$g$ & gravitational acceleration $\left[\mathrm{ms}^{-2}\right]$ & Greek symb & \\
\hline$k$ & thermal conductivity $\left[\mathrm{Wm}^{-1} \mathrm{~K}^{-1}\right]$ & $\alpha$ & thermal diffusivity $\left[\mathrm{m}^{2} \mathrm{~s}^{-1}\right]$ \\
\hline$L$ & length of the cavity [m] & $\beta$ & thermal expansion coefficient $\left[\mathrm{K}^{-1}\right]$ \\
\hline$N u$ & Nusselt number & $\phi$ & solid volume fraction \\
\hline$p$ & dimensional pressure $\left[\mathrm{Nm}^{-2}\right]$ & $\gamma$ & penalty parameter \\
\hline$P$ & dimensionless pressure & $v$ & kinematic viscosity of the fluid $\left[\mathrm{m}^{2} \mathrm{~s}^{-1}\right]$ \\
\hline $\operatorname{Pr}$ & Prandtl number & $\theta$ & dimensionless temperature \\
\hline$R a$ & Rayleigh number & $\rho$ & density of the fluid $\left[\mathrm{kgm}^{-3}\right]$ \\
\hline$T$ & dimensional temperature $[\mathrm{K}]$ & $\psi$ & stream function \\
\hline$u$ & $x$-component of velocity $\left[\mathrm{ms}^{-1}\right]$ & Subscripts & \\
\hline$U$ & $x$-component of dimensionless velocity & $a v$ & average \\
\hline$v$ & $y$-component of velocity $\left[\mathrm{ms}^{-1}\right]$ & $c$ & cold \\
\hline$V$ & $y$-component of dimensionless velocity & $h$ & hot \\
\hline
\end{tabular}




$\begin{array}{llll}x & \text { distance along } x \text {-coordinate }[\mathrm{m}] & f & \text { base fluid } \\ X & \text { dimensionless distance along } x \text {-coordinate } & n f & \text { nanofluid } \\ y & \text { distance along } y \text {-coordinate }[\mathrm{m}] & S & \text { solid particle }\end{array}$

\section{Introduction}

The natural convection in enclosures is encountered in widespread applications such as chemical reactors, solar energy collectors, heat exchangers, cooling of electronic devices, grain storage, storage of radioactive waste, fire control and chemical, food and metallurgical industries, etc.

Nanoscience and nanotechnology are the study of extremely small things and they can be used across all other science fields, such as chemistry, biology, physics, material science and engineering. Natural convection in enclosures filled with nanofluids has been studied by many authors. Triveni et al. (2016) performed the numerical investigation of laminar natural convection in an arch enclosure filled with $\mathrm{Al}_{2} \mathrm{O}_{3}$-water based nanofluid. The results reported that the heat transfer rate is enhanced with the increment in the volume fraction of the nanoparticles up to 5\% and after that it is decreased gradually. Ismael et al. (2014) have studied natural convection heat transfer in an arc shape wall porous cavity filled with nanofluid. Natural convection and radiation in circular and arc cavity has been investigated by Ferdous et al. (2009).

Recently, Ahmed and Nasrin (2016) have studied convective flow in a prismatic cavity using water-based nanofluids and found higher heat transfer rate. Results illustrated that magnitude of mean velocity becomes superior for water/CuO nanofluid compared to water/Cu nanofluid. Before this, Ahmed et al. (2015) analyzed heatline for natural convection flows within prismatic enclosures. Free convective flow of nanofluid with two nanoparticles inside a complicated cavity has been studied and investigated by Nasrin and Alim (2013). The authors showed that by using water based nanofluid with double nanoparticle as heat transfer medium is more effective in natural convection flow. In fact, heat transfer enhancement in various two dimensional enclosures utilizing nanofluids are investigated by Nasrin and Parvin (2012), Parvin et al. (2014), Parvin et al. (2012), Sheikhzadeh et al. (2011) and Abu-Nada et al. (2010). Triveni et al. (2015) analyzed convective heat transfer in an arch enclosure. It was reported that the varying height of the arch cavity and Rayleigh number playing a significant role in heat transfer rate. A few earlier works, namely, Nasr et al. (2006), Varol et al. (2006) and Koca et al. (2007), which involve studies on natural convection in partially heated enclosures for different boundary conditions in air and water-filled enclosures have been studied extensively. Ismael and Chamkha (2015) studied mixed convection heat transfer and fluid flow fields inside a lid-driven cavity. The results showed that the behavior of Nusselt number is different from Richardson number depending on the direction of the lid. The inclination angle of the side walls was found to have a significant effect on Nusselt number when Richardson number was relatively low.

Davis (1983) obtained a benchmark numerical solution of buoyancy driven flow in a square cavity with vertical walls at different temperatures and adiabatic horizontal walls. Davis and Jones (1983) presented a comparative study on different contributed solutions to the same problem. These solutions covered the range of Rayleigh numbers from $10^{3}$ to $10^{6}$. The effects of vertical parabolic walls on natural convection in a parabolic enclosure have investigated numerically by Mustafa (2011). Diaz and Winston (2008) have analyzed the interaction of natural convection and surface radiation in two-dimensional parabolic cavities heated from below with insulated walls and flat top and bottom walls numerically. Hussein and Hussain (2016), Hussein et al. (2016), Hussein and Mustafa (2017) and Chand et al. (2015) used different nanofluids in natural convection laminar flow in porous or non-porous medium considering different shapes of cavity with different boundary conditions. The authors showed heatline vizualization, magnetohydrodynamic effect, heat source effect, direct is oflux heating effect, constant heated bottom wall effect in the nanofluid flow.

The brief literature survey revealed that the closed cavities such as square, rectangular, circular, prismatic, rhombic, parabolic and triangular filled with air and water have been studied extensively to examine the heat transfer rate. So far, a very few studies have been carried out in arch cavity. Hence, the aim of this work is to investigate the fluid flow and heat transfer mechanism on steady-state solutions in circular and arc-square enclosures filled with water/Cu nanofluid as well as base fluid. In this present research, two new correlations have been developed among the obtained results of various parameters. This research will also help in economic and efficient design of such heat trans fer equipments in practical applications. 


\section{Mathematical Formulation}

The physical diagram of the problem and the boundary conditions are shown in Fig. 1(a) and 1(b). They are circular and arc-square cavities filled with water/Cu nanofluid as well as base fluid. Diameter of the cavity is $H$, where adiabatic horizontal sides are $0.57 \mathrm{H}$. The left wall is heated with a constant temperature $T_{h}$ and the cold wall is at a constant temperature $T_{c}$. The horizontal walls are kept as perfectly insulated. Laminar fluid flow and constant fluid properties are assumed here. The gravitational acceleration is considered in the normal vertical direction. The fluid outside the enclosures is maintained an ambient temperature $T_{a}$. In the present study, Rayleigh number is varied from $10^{3}$ to $10^{6}$ and the Prandtl number is taken from 4.2 to 6.2 .

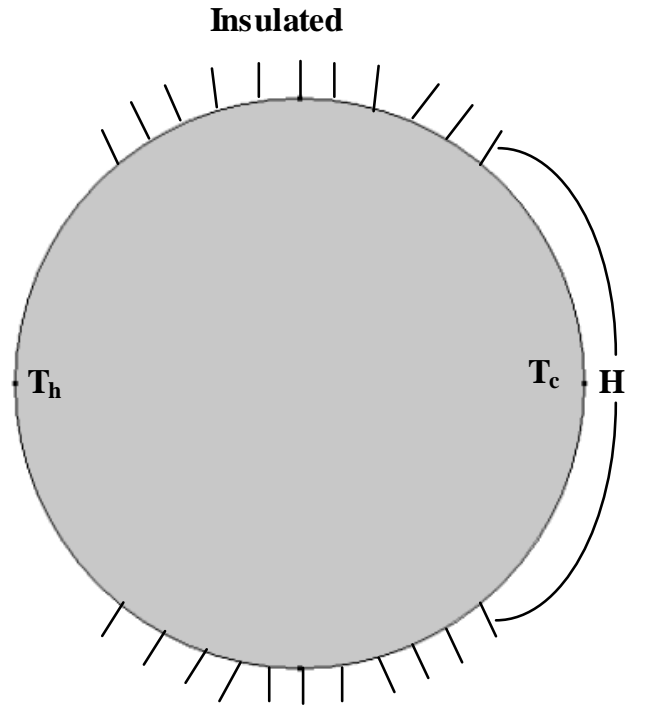

Insulated

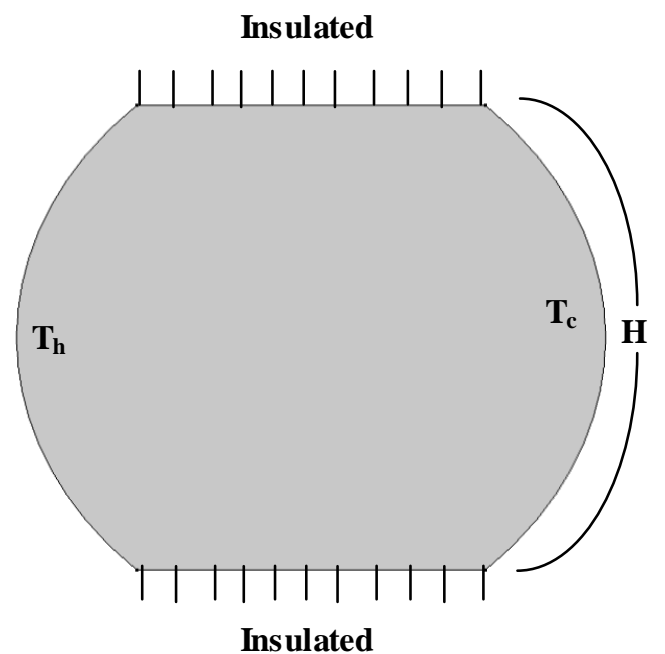

(b)

(a)

Figure 1: Physical model of (a) circular and (b) arc-square enclosure

The steady laminar incompressible free convective fluid flow is accounted in the current investigation. The gravitational force works in the opposite of $y$-direction. Constant physical and thermal characteristics of the fluid are used. The Boussinesq approximation is valid. The flow is governed by the following equations of conservation of mass, momentum and energy:

$$
\begin{aligned}
& \frac{\partial u}{\partial x}+\frac{\partial v}{\partial y}=0 \\
& \rho_{n f}\left(u \frac{\partial u}{\partial x}+v \frac{\partial u}{\partial y}\right)=-\frac{\partial p}{\partial x}+\mu_{n f}\left(\frac{\partial^{2} u}{\partial x^{2}}+\frac{\partial^{2} u}{\partial y^{2}}\right) \\
& \rho_{n f}\left(u \frac{\partial v}{\partial x}+v \frac{\partial v}{\partial y}\right)=-\frac{\partial p}{\partial y}+\mu_{n f}\left(\frac{\partial^{2} v}{\partial x^{2}}+\frac{\partial^{2} v}{\partial y^{2}}\right)+g \rho_{n f} \beta_{n f}\left(T-T_{c}\right) \\
& u \frac{\partial T}{\partial x}+v \frac{\partial T}{\partial y}=\alpha_{n f}\left(\frac{\partial^{2} T}{\partial x^{2}}+\frac{\partial^{2} T}{\partial y^{2}}\right)
\end{aligned}
$$

Relationships between properties of nanofluid $(n f)$, pure fluid $(f)$ and pure solid $(s)$ are given by

- Density: $\rho_{n f}=(1-\phi) \rho_{f}+\phi \rho_{s}$

- Heat capacitance: $\left(\rho C_{p}\right)_{n f}=(1-\phi)\left(\rho C_{p}\right)_{f}+\phi\left(\rho C_{p}\right)_{s}$

- Thermal expansion coefficient: $\beta_{n f}=(1-\phi) \beta_{f}+\phi \beta_{s}$

- Thermal diffusivity: $\alpha_{n f}=k_{n f} /\left(\rho C_{p}\right)_{n f}$ 
- In the current study, the viscosity of the nanofluid is considered by the Pak and Cho correlation (1998). This correlation is given as

$\mu_{n f}=\mu_{f}\left(1+39.11 \phi+533.9 \phi^{2}\right)$

- The effective thermal conductivity of the nanofluid is approximated by the Maxwell-Garnett model (1904) as $k_{n f}=k_{f} \frac{k_{s}+2 k_{f}-2 \phi\left(k_{f}-k_{s}\right)}{k_{s}+2 k_{f}+\phi\left(k_{f}-k_{s}\right)}$

The following dimensionless dependent and independent variables are used to make Equations (1) through (4) non-dimensional:

$X=\frac{x}{L}, \quad Y=\frac{y}{L}, U=\frac{u L}{\alpha_{f}}, \quad V=\frac{v L}{\alpha_{f}}, \theta=\frac{T-T_{c}}{T_{h}-T_{c}}, P=\frac{p L^{2}}{\rho_{f} \alpha_{f}^{2}}, \operatorname{Pr}=\frac{v_{f}}{\alpha_{f}}, R a=\frac{g \beta\left(T-T_{c}\right) L^{3}}{v_{f} \alpha_{f}}$

After substitution, the dimensionless equations are as follows:

$$
\begin{aligned}
& \frac{\partial U}{\partial X}+\frac{\partial V}{\partial Y}=0 \\
& U \frac{\partial U}{\partial X}+V \frac{\partial U}{\partial Y}=-\frac{\rho_{f}}{\rho_{n f}} \frac{\partial P}{\partial X}+\operatorname{Pr} \frac{v_{n f}}{v_{f}}\left(\frac{\partial^{2} U}{\partial X^{2}}+\frac{\partial^{2} U}{\partial Y^{2}}\right) \\
& U \frac{\partial V}{\partial X}+V \frac{\partial V}{\partial Y}=--\frac{\rho_{f}}{\rho_{n f}} \frac{\partial P}{\partial Y}+\operatorname{Pr} \frac{v_{n f}}{v_{f}}\left(\frac{\partial^{2} V}{\partial X^{2}}+\frac{\partial^{2} V}{\partial Y^{2}}\right)+\operatorname{RaPr} \frac{(1-\phi) \rho_{f} \beta_{f}+\phi \rho_{s} \beta_{s}}{\rho_{n f} \beta_{f}} \theta \\
& U \frac{\partial \theta}{\partial X}+V \frac{\partial \theta}{\partial Y}=\frac{\alpha_{n f}}{\alpha_{f}}\left(\frac{\partial^{2} \theta}{\partial X^{2}}+\frac{\partial^{2} \theta}{\partial Y^{2}}\right)
\end{aligned}
$$

In Equation (5), $X$ and $Y$ are the dimensionless distances along $x$ - and $y$-coordinate, respectively, $L$ is vertical depth of the cavity, i.e. perpendicular distance from the bottom wall to the top wall, $U$ and $V$ are the corresponding velocity components along the coordinate axes, $P$ denotes the dimensionless pressure whereas $P r$ and $R a$ denote Prandtl and Rayleigh numbers, respectively.

Analysis of fluid motion is displayed by means of streamfunction which is obtained from velocity components $U$ and $V$. The relationships between streamfunction and velocity components for two-dimensional flows are

$$
\begin{gathered}
U=\frac{\partial \psi}{\partial Y} \text { and } V=-\frac{\partial \psi}{\partial X} \\
\text { which give a single equation } \frac{\partial^{2} \psi}{\partial X^{2}}+\frac{\partial^{2} \psi}{\partial Y^{2}}=\frac{\partial U}{\partial Y}-\frac{\partial V}{\partial X}
\end{gathered}
$$

The positive sign of $\psi$ denotes anticlockwise circulation and the clockwise circulation is represented by the negative sign of $\psi$. The no-slip condition is valid at all boundaries as there is no cross-flow. Hence $\psi=0$ is used for boundaries.

The average Nusselt number, average temperature and average velocity may be expressed as

$$
N u=-\frac{1}{S} \frac{k_{n f}}{k_{f}} \int_{0}^{S} \frac{\partial \theta}{\partial N} d S, \quad \theta_{a v}=\frac{1}{\bar{V}} \int \theta d \bar{V} \quad \text { and } \quad V_{a v}=\frac{1}{\bar{V}} \int V d \bar{V}
$$

where $\frac{\partial \theta}{\partial N}=\sqrt{\left(\frac{\partial \theta}{\partial X}\right)^{2}+\left(\frac{\partial \theta}{\partial Y}\right)^{2}} ; S$ is the dimensionless periphery, $N$ is the normal coordinate along the boundary and $\bar{V}$ is the volume to be accounted. 


\section{Numerical Implementation}

The Galerkin finite element method (Taylor and Hood (1973) and Dechaumphai (1999)) is used to solve the non-dimensional governing equations along with boundary conditions for the considered problem. The equation of continuity has been used as a constraint due to mass conservation and this restriction may be used to find the pressure distribution. The finite element method of Reddy (1994) is used to solve the Eqns. (6) - (9) where the pressure $P$ is eliminated by a constraint. The continuity equation is automatically fulfilled for large values of this penalty constraint. Then the velocity components $(U, V)$ and temperature $(\theta)$ are expanded using a basis set. The Galerkin finite element technique yields the subsequent nonlinear residual equations. Three point Gaussian quadrature is used to evaluate the integrals in these equations. The non-linear residual equations are solved using Newton-Raphson method to determine the coefficients of the expansion. The convergence of solutions is assumed when the relative error for each variable between consecutive iterations is recorded below the convergence criterion $\varepsilon$ such that $\left|\Psi^{n+1}-\Psi^{n}\right| \leq 10^{-4}$, where $n$ is the number of iteration and $\Psi$ is a function of $U, V$ and $\theta$.

\subsection{Mesh generation}

Mesh generation is basically a discrete representation of the geometric domain on which the problem is to be solved. The discrete locations are defined by the numerical grid, at which the variables are to be calculated. Figures 2(a)-(b) display the finite element mesh of the present physical domain for circular and arc enclosures respectively. The green and blue colors in the Figures 2(a)-(b) represent element color and wireframe color respectively in the finite element meshing of computational domain.

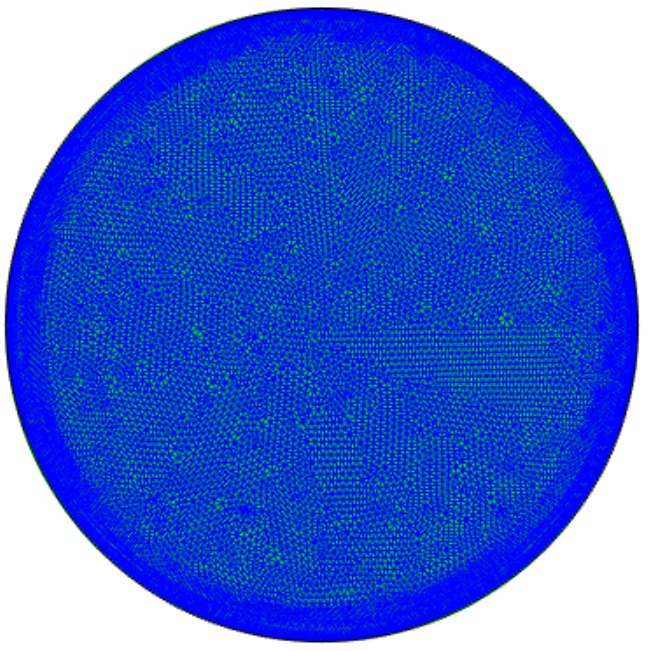

(a)

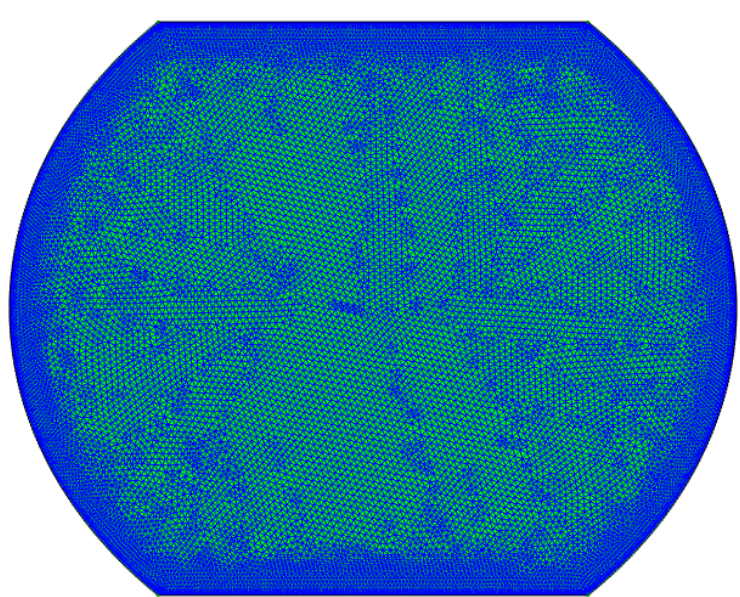

(b)

Figure 2: Finite element meshing of (a) circular and (b) arc-square cavities

\subsection{Grid independent test}

A grid-independent solution in both circular and arc enclosures is conducted for $2 \%$ concentrated water/Cu nanofluid at $\operatorname{Pr}=5.8$ and $R a=10^{4}$. In the present work, five different non-uniform grid systems are examined with the following number of elements within the resolution field: 5,400; 13,526; 20,914; 54,996 and 96,487 for circular cavity and 6,$832 ; 17,186 ; 27,882 ; 74,044$ and $1,20,543$ for arc cavity. The numerical scheme is carried out for highly precise key in the average Nusselt number $(\mathrm{Nu})$ for the aforesaid elements to develop an understanding of the grid fineness as shown in Table 1. The scale of the average Nusselt numbers for the fourth column elements show a little difference with the results obtained for the fifth column elements. Hence, considering the non-uniform grid system of 54,996 and 74,044 elements for circular and arc cavities respectively are preferred for the computation. 
Table 1: Grid sensitivity check at $\operatorname{Pr}=5.8$ and $R a=10^{4}$

\begin{tabular}{|l|l|l|l|l|l|}
\hline Elements (Circular) & 5,400 & 13,526 & 20,914 & 54,996 & 96,487 \\
\hline $\mathrm{Nu}$ & 2.42877 & 2.97125 & 3.51931 & 4.15435 & 4.15437 \\
\hline Time (s) & 104 & 210 & 421 & 624 & 1024 \\
\hline Elements (Arc-square) & 6,832 & 17,186 & 27,882 & 74,044 & $1,20,543$ \\
\hline $\mathrm{Nu}$ & 2.25323 & 2.81227 & 3.48521 & 4.02342 & 4.02348 \\
\hline Time (s) & 127 & 308 & 581 & 897 & 1295 \\
\hline
\end{tabular}

\subsection{Thermo-physical properties}

The thermo-physical properties of the nanoparticle are taken from Nasrin and Alim (2013) and given in Table 2.

Table 2: Thermo-physical properties of base fluid and nanoparticles

\begin{tabular}{lll}
\hline Properties & Base fluid & Nanoparticle \\
\hline$C_{p}(\mathrm{~J} / \mathrm{kgK})$ & 4179 & 385 \\
$\rho\left(\mathrm{kg} / \mathrm{m}^{3}\right)$ & 997.1 & 8933 \\
$k(\mathrm{~W} / \mathrm{mK})$ & 0.613 & 400 \\
$\alpha \times 10^{7}\left(\mathrm{~m}^{2} / \mathrm{s}\right)$ & 1.47 & 1163.1 \\
$\mu \times 10^{6}\left(\mathrm{Ns} / \mathrm{m}^{2}\right)$ & 855 & ----- \\
\hline
\end{tabular}

\section{Results and Discussion}

In this section, numerical results in terms of isotherms and streamlines are displayed for various values of buoyancy force namely Rayleigh number $(R a)$ and viscous force namely Prandtl number $(P r)$ filled with water/Cu nanofluid as well as base fluid in circular and arc-square enclosures. Considered values of $R a$ are $10^{3}$, $10^{4}, 10^{5}$ and $10^{6}$ while $\operatorname{Pr}$ are 4.2, 5.2, 5.8 and 6.2. The variation of temperature gradient of fluids inside cavities is calculated in terms of average Nusselt number. In addition, the values of the average Nusselt number, mean temperature and average subdomain velocity of water/ $\mathrm{Cu}$ nanofluid as well as base fluid inside the circular and arc-square cavities have been shown in the following sub sections.

\subsection{Effect of Rayleigh number}

Figures 3(a)-(b) illustrate the effect of Rayleigh number, $R a$ on isothermal lines in circular and arc-square enclosures filled with $2 \%$ concentrated water/Cu nanofluid at $\mathrm{Pr}=5.8$. The colors of streamlines indicate hot and cold domains in the cavities. Red, green and blue colors indicate hot, less hot and cold isothermal lines respectively. At constant temperatures, the left and right surfaces of the cavity are, respectively, heated and cooled and its horizontal walls are adiabatic. The isotherm contours are distributed throughout for both the cavities. The thermal plumes are becoming less dense near the horizontal walls. They are shifted towards the right cold wall. The thermal plumes are started from the left corner of the cavity, they move upward, flow throughout the cavity and impinged to the right corner of the cavity. With the increase of $R a$, the plumes are shifted towards the cold wall and at higher value of $R a$, it sticks to the cold wall. For arc-square cavity, as $R a$ increased to $10^{5}$, the plumes are almost horizontal near the center of the cavities. For circular cavity, the motions of the is otherms are very slow at low $R a$. However, as $R a$ increases the temperature gradient between hot and cold wall become more severe. At higher $R a=\left(10^{5}, 10^{6}\right)$, the is othermal plumes become parallel to each other at the center of the cavity.

The effect of Rayleigh number, $R a$ on streamlines of water/copper nanofluid (2\% solid volume fraction) in circular and arc-square enclosures at $\operatorname{Pr}=5.8$ is depicted in Figures 4(a)-(b). It is observed that the nanofluid in the cavities moves from the left side to the right in a clockwise motion. At $R a=10^{3}$, the rotating cells are circular while with the increasing value of $R a$ deformation took place indicating the greater strength of stream functions. For circular cavity, the lowest value of $R a$ effects the weak flow strength of the nanofluid. 

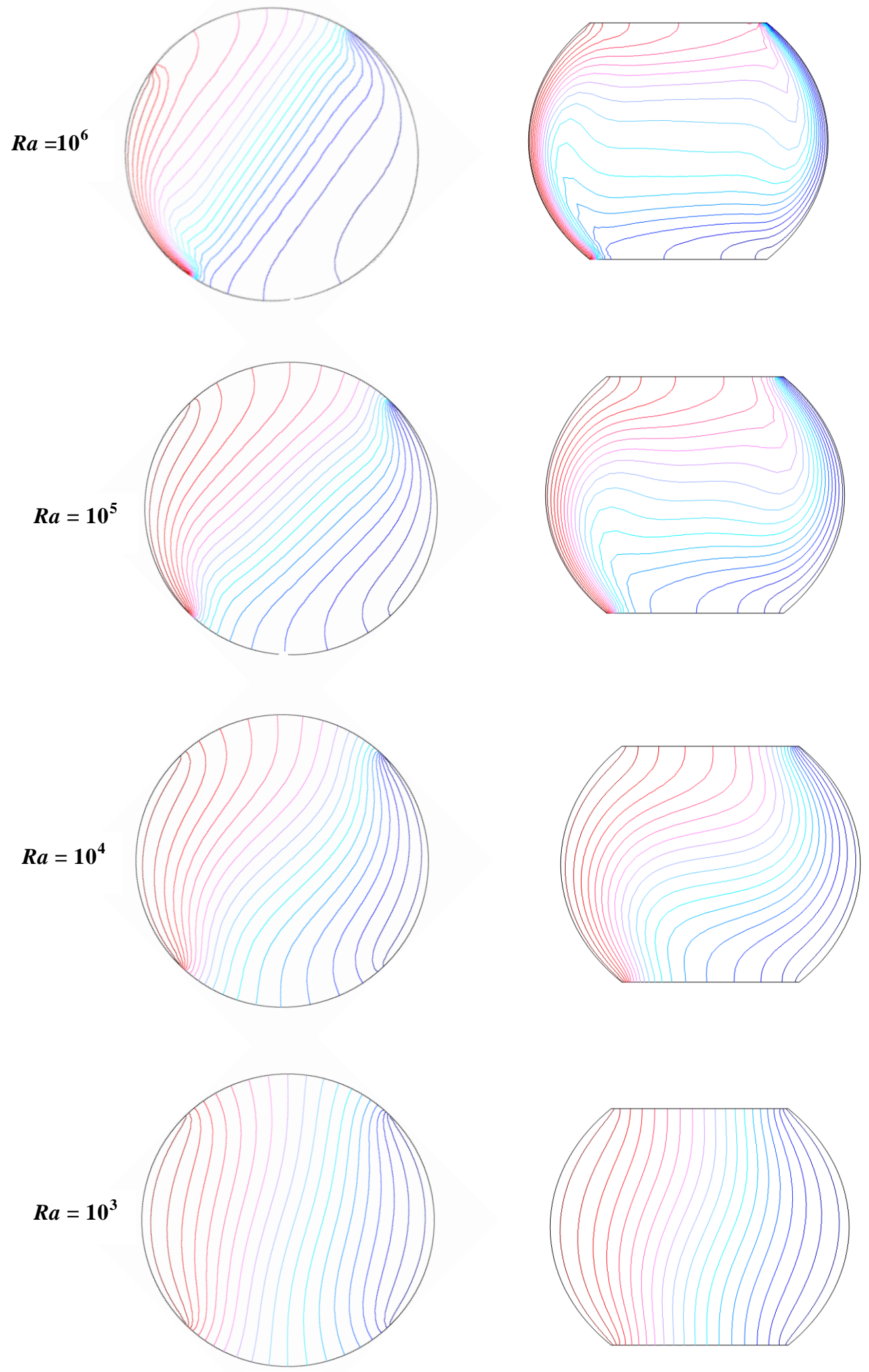

(a)

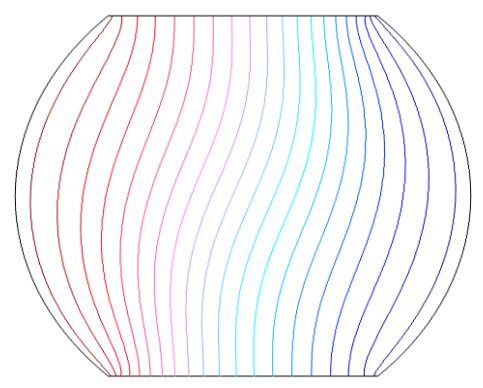

(b)

Figure 3: Is othermal lines plot for the variation of $R a$ in (a) circular and (b) arc enclosures 

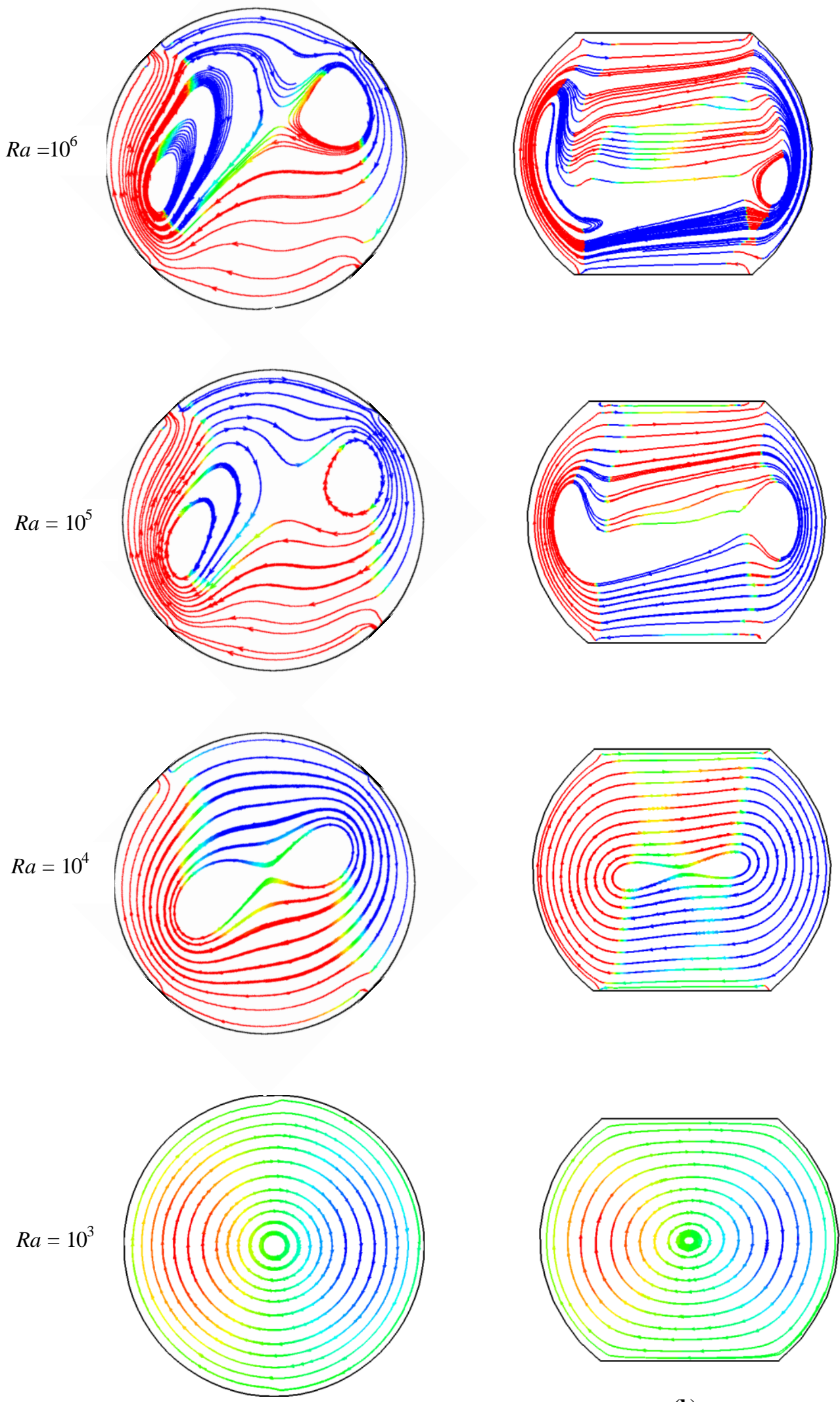

(a)

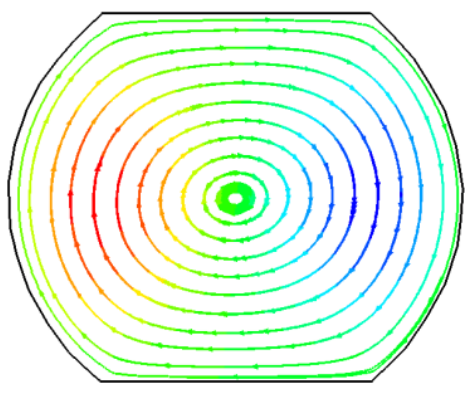

(b)

Figure 4: Streamlines plot for the variation of $R a$ in (a) circular and (b) arc enclosures 
With the increasing value of $R a=10^{5}$ there are two circular core cells of the streamline and later with $R a=10^{6}$ they turned into irregular shaped. At $R a=10^{5}$, the core cell length increases for the arc-square cavity and as the Rayleigh number increases to $R a=10^{6}$, the core cell length extended and turned into peculiar shape. Thus the flow strength of the nanofluid increases as values of $R a$ increases.

\subsection{Effect of Prandtl number}

The effect of various Prandtl numbers, namely, $\operatorname{Pr}=(6.2,5.8,5.2$ and 4.2) on isotherms in circular and arcsquare enclosures filled with $2 \%$ concentrated water/Cu nanofluid at $R a=10^{4}$ are illustrated in Figures 5(a)-(b). The pattern of the is othermal lines is different for two types of enclosures due to the shape of enclosures. The lines are more bend in arc-square enclosure than circular enclosure. Heat is transferred from left hot surface to right cold surface in the cavities. In arc-square enclosures, is othermal lines are almost parallel for lower values of $\mathrm{Pr}$. At $\mathrm{Pr}=6.2$, the significant difference in isothermal lines are observed at the center of the arc-square enclosure. The is othermal lines become more bend at high value of $\operatorname{Pr}=6.2$. The thickness of the thermal boundary layer is directly related to the viscous effect of the fluid. Higher the thickness of the thermal boundary layer induces high viscous effect and less the heat transfer.

Figures 6(a)-(b) display the variation in streamlines of water/copper nanofluid (2\% solid volume fraction) in circular and arc-square enclosures for different values of Prandtl number at $R a=10^{4}$. The streamlines are looked qualitatively quite similar for both cavities. Inside the arc-square cavities, the streamline contours are distributed throughout the whole cavity. At $\operatorname{Pr}=4.2$, the pattern of the streamlines are monotonic, smooth and symmetric throughout the cavities. For circular enclosure, the core cell of the streamline turned into oval shaped from circular pattern and at $\operatorname{Pr}=6.2$, they become irregular shaped with two vortices. It is essential to mention that in the circular cavity the streamlines are less dense compared to arc-square cavity for different values of Prandtl numbers. As Prandtl number increased to 6.2, the streamlines in the cavities become more strengthen representing that the magnitude of the stream function is increasing. It is noteworthy to mention that with the increasing value of the Prandtl number the streamlines are less dense near the central vertical line. It is obs erved that the patterns of the circulation cells are affected for both cavities with the variation of $P r$.

\subsection{Average Nusselt number}

Figures 7(a)-(b) show the distribution of the average Nusselt number for the circular and arc cavities versus the Rayleigh number, $R a\left(=10^{3}, 10^{4}, 10^{5}\right.$ and $\left.10^{6}\right)$ using $2 \%$ concentrated water/ $\mathrm{Cu}$ nanofluid and clear water respectively at $\operatorname{Pr}=5.8$. The average Nusselt number for the circular and arc cavities increases with rising values of Rayleigh number and it is utilized to represent the overall heat transfer rate within the domain. For water/Cu nanofluid, the rate of heat transfer increases by $28 \%$ and $25 \%$ for circular and arc enclosures respectively with the rising values of buoyancy force. At the value of buoyancy force, $R a=10^{4}$ higher heat transfer rate is observed by approximately $2.7 \%$ for circular enclosure than arc cavity. On the other hand, for clear water, the rate of heat transfer increases by $23 \%$ for circular, $20 \%$ for arc enclosure. About $2.5 \%$ increased rate of heat transfer is found for circular than arc cavity at $R a=10^{4}$. The average Nusselt number increases with increasing values of Rayleigh number due to domination of convective mode heat transfer. Heat transfer rate increases approximately $5 \%$ by using water/ $\mathrm{Cu}$ nanofluid (solid volume fraction $2 \%$ ) than base fluid for both type of cavities flow.

Figures 8(a)-(b) demonstrate the distribution of the average Nusselt number for the circular and arc cavities versus the Prandtl number, $\operatorname{Pr}(=4.2,5.2,5.8$ and 6.2) for water/Cu nanofluid and clear water respectively at $R a$ $=10^{4}$. The rate of heat transfer increases by $23 \%$ for circular enclosure and $21 \%$ for arc enclosure by using water/Cu nanofluid as heat transfer medium with the increasing values of viscous force. At the fixed $\operatorname{Pr}=5.8$, rate of heat transfer becomes higher of about $2.2 \%$ for circular than arc cavity. For water, the rate of heat transfer increases by $18 \%$ for circular, $16 \%$ for arc cavity for the variation of Prandtl number from 4.2 to 6.2. Approximately $2.1 \%$ increment of heat transfer is found for circular than arc cavity at $\operatorname{Pr}=5.8$. Thus, heat transfer rate is found to be higher for water/Cu nanofluid with $2 \%$ solid volume fraction than clear water. About $2.7 \%$ higher heat transfer rate is obtained for circular cavity than that of arc cavity using water/Cu nanofluid at $R a=10^{4}$ and $\operatorname{Pr}=5.8$. 

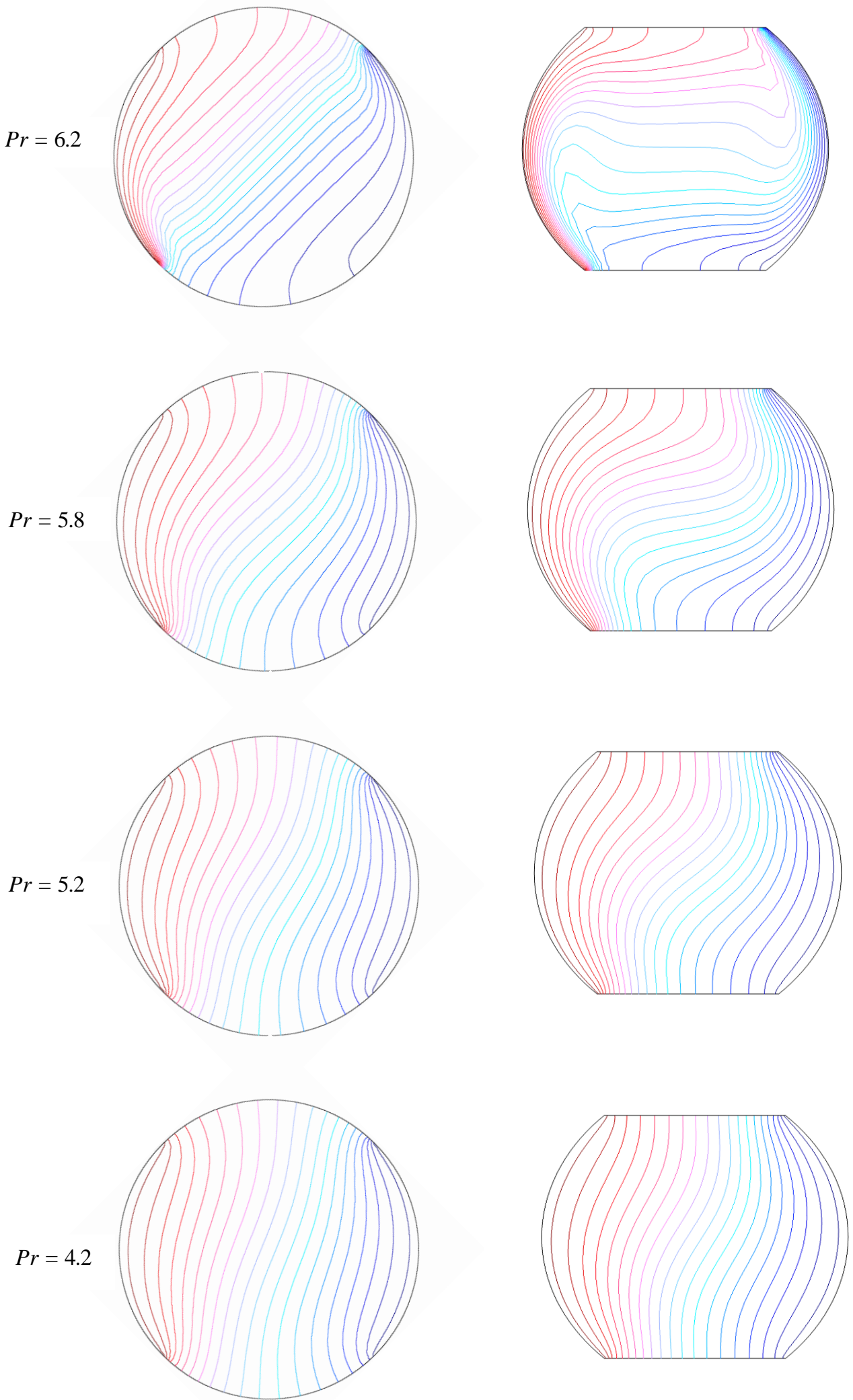

(a)

(b)

Figure 5: Is othermal lines for the variation of $\operatorname{Pr}$ in (a) circular and (b) arc enclosures 

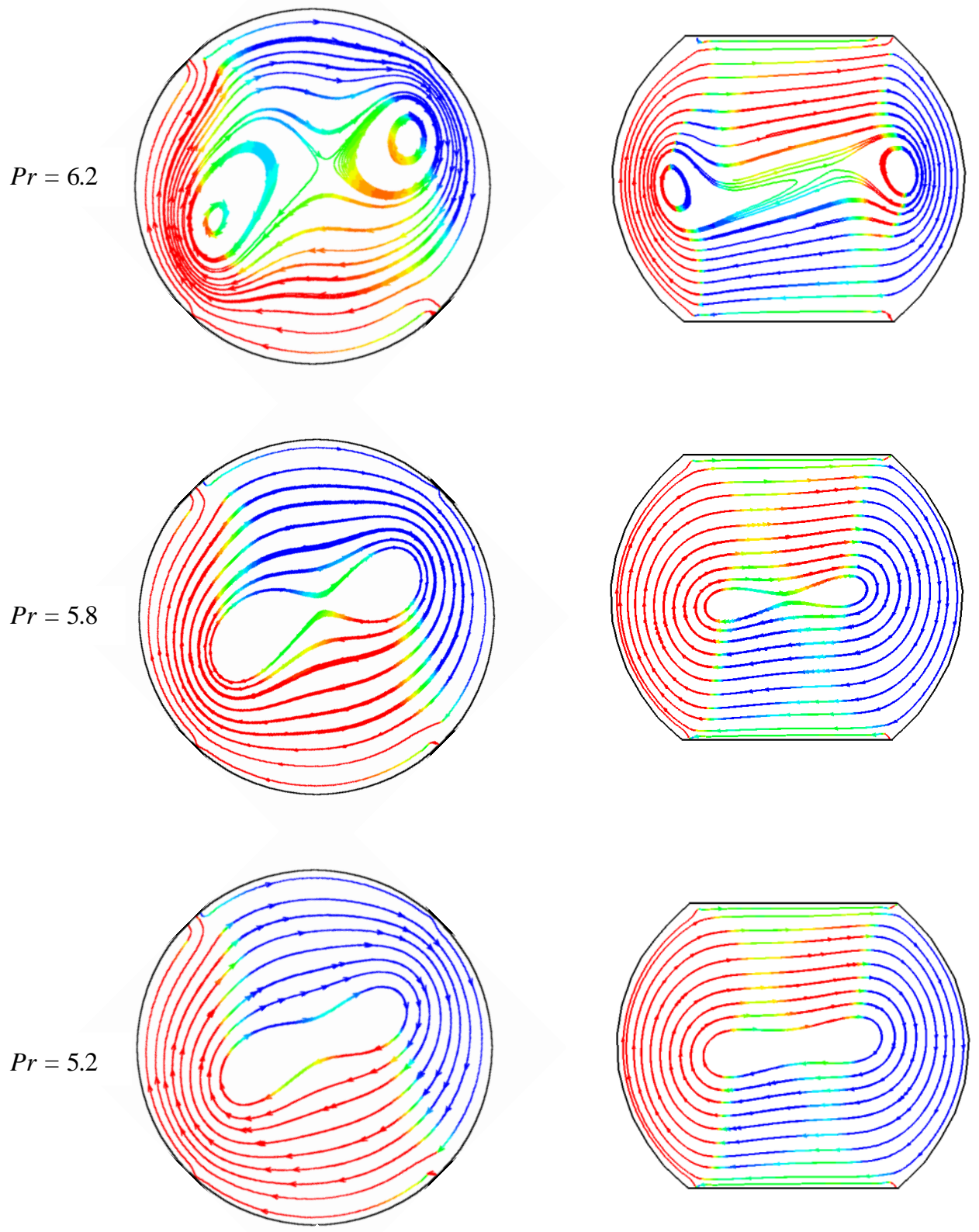

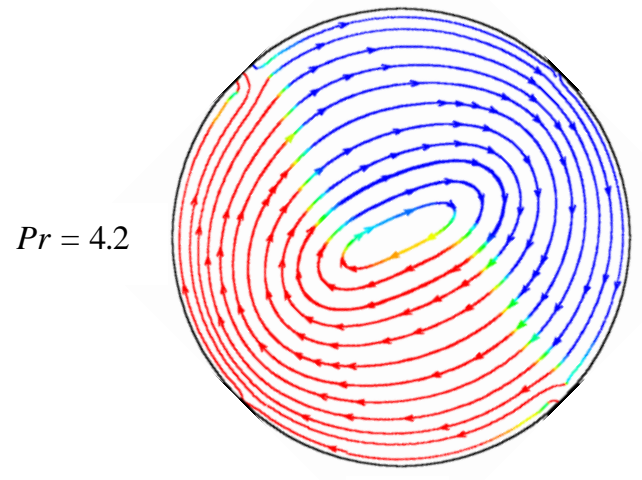

(a)

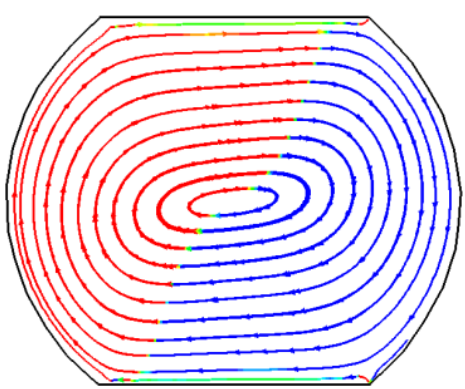

(b)

Figure 6: Streamlines for the variation of $\mathrm{Pr}$ in (a) circular and (b) arc enclosures 


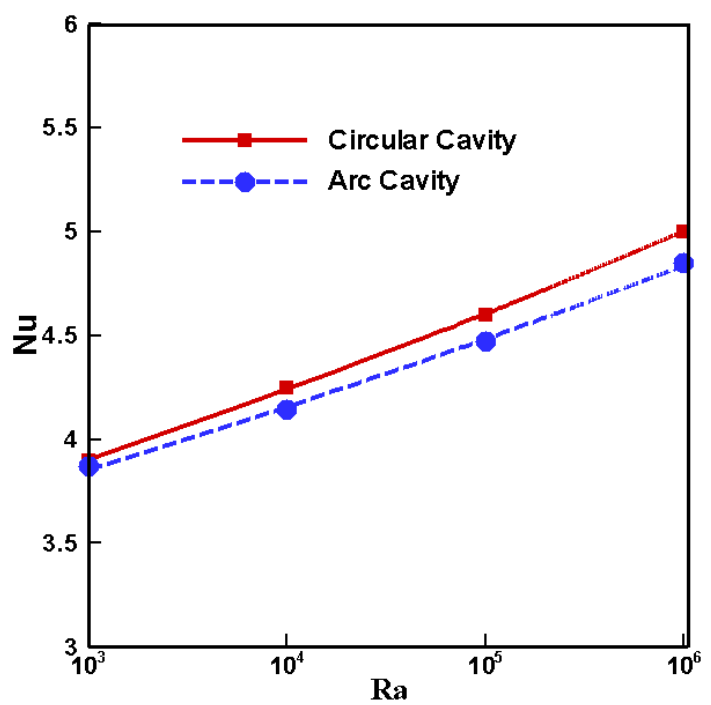

(a)

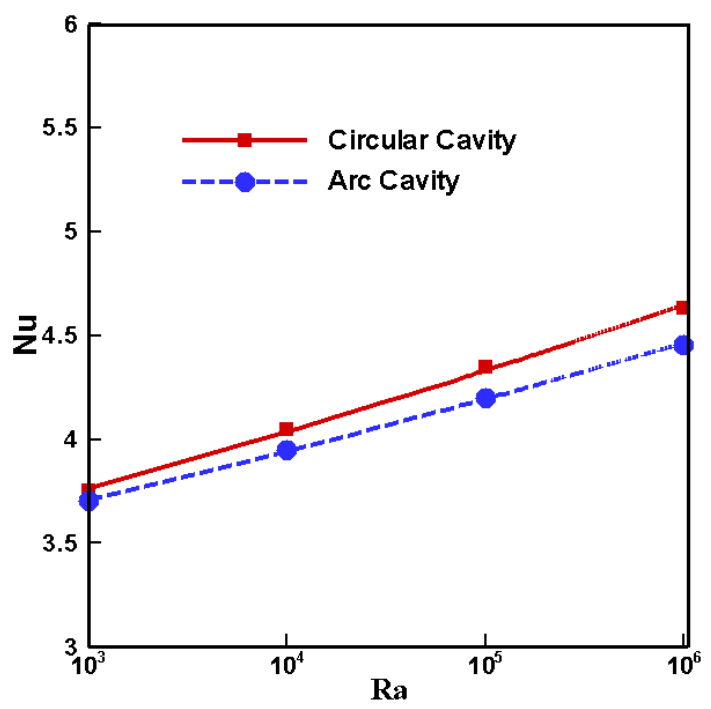

(b)

Figure 7: Heat transfer rate versus $R a$ using (a) water/Cu nanofluid and (b) water at $P r=5.8$

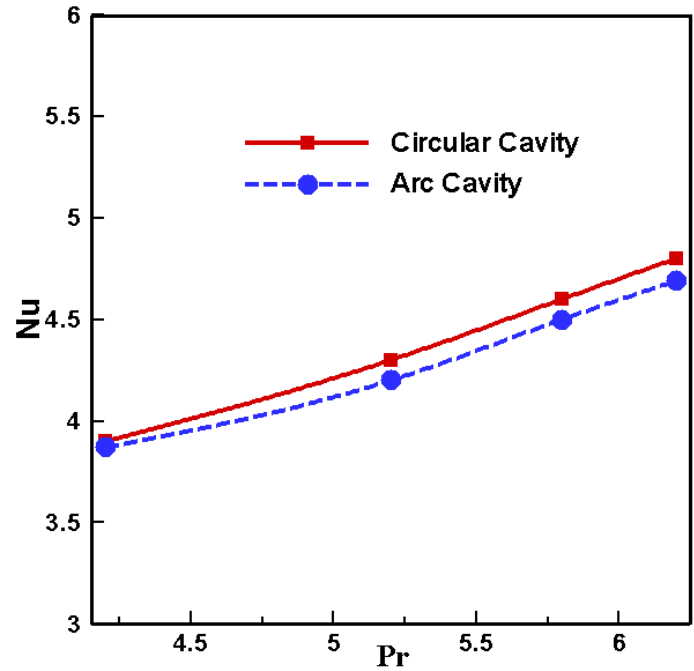

(a)

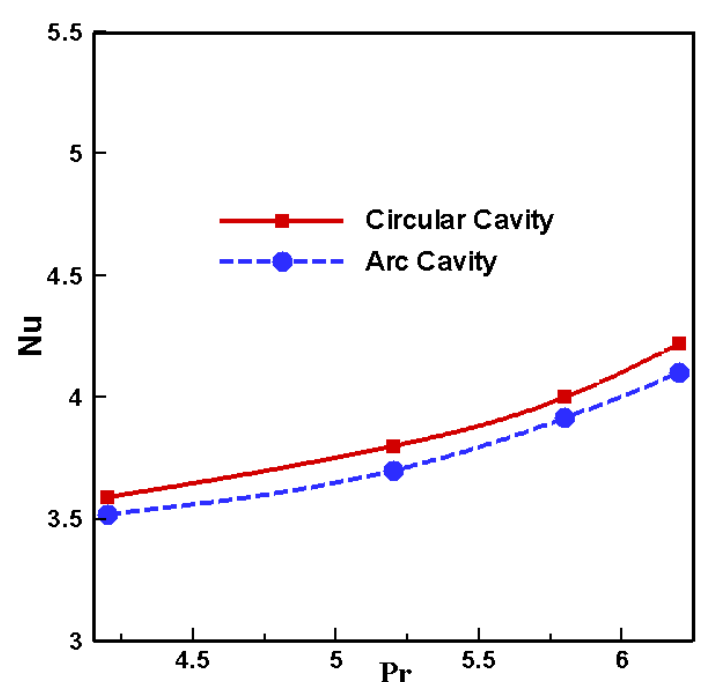

(b)

Figure 8: Heat transfer rate versus $\operatorname{Pr}$ using (a) water/Cu nanofluid and (b) water at $\mathrm{Ra}=10^{4}$

\subsection{Average temperature}

Figures 9(a)-(b) show the distribution of average temperature of water/Cu nanofluid ( $2 \%$ solid volume fraction) and base fluid respectively in the case of circular and arc cavities versus the Rayleigh number, $R a\left(=10^{3}, 10^{4}\right.$, $10^{5}$ and $\left.10^{6}\right)$ at $\operatorname{Pr}=5.8$. It is seen that the average temperature of water/Cu nanofluid as well as pure water for circular and arc cavities increases with the increasing values of buoyancy force. Value of mean temperature becomes higher for water/Cu nanofluid than base fluid. In addition, values of average temperature of nanofluid/base fluid becomes higher in the case of circular cavity than arc-square cavity.

Mean temperature of water/Cu nanofluid and clear water against $\operatorname{Pr}(=4.2,5.2,5.8$ and 6.2) for circular and arc cavities are depicted in Figures 10 (a)-(b) respectively at $R a=10^{4}$. For both the parameters, similar trend of mean temperature of water/ $\mathrm{Cu}$ nanofluid and clear water are observed inside the circular and arc cavities. Higher concentration of solid particle enhances thermal conductivity as well as mean temperature of the working water/ $\mathrm{Cu}$ nanofluid than pure water. The performance of mean temperature inside circular cavities is found to be higher than arc enclosures. 


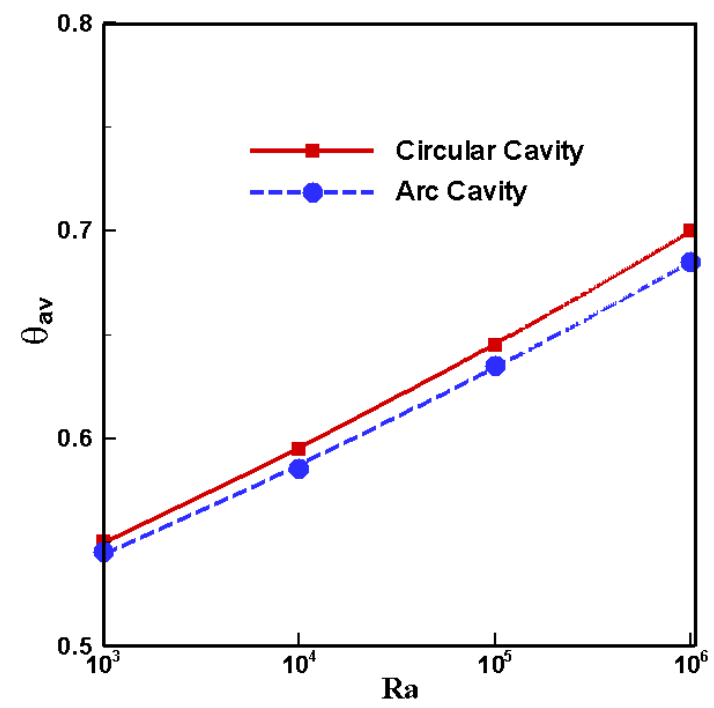

(a)

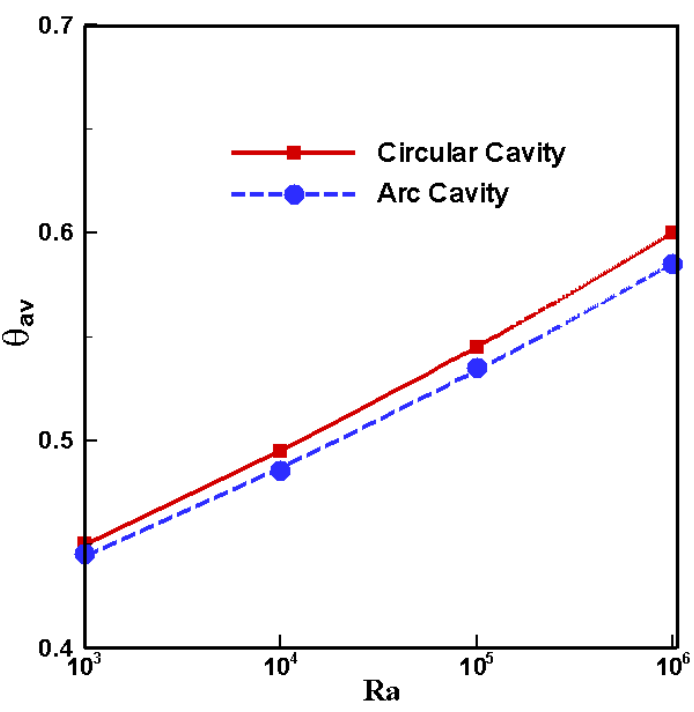

(b)

Figure 9: Mean temperature versus $R a$ using (a) water/Cu nanofluid and (b) water at $\operatorname{Pr}=5.8$

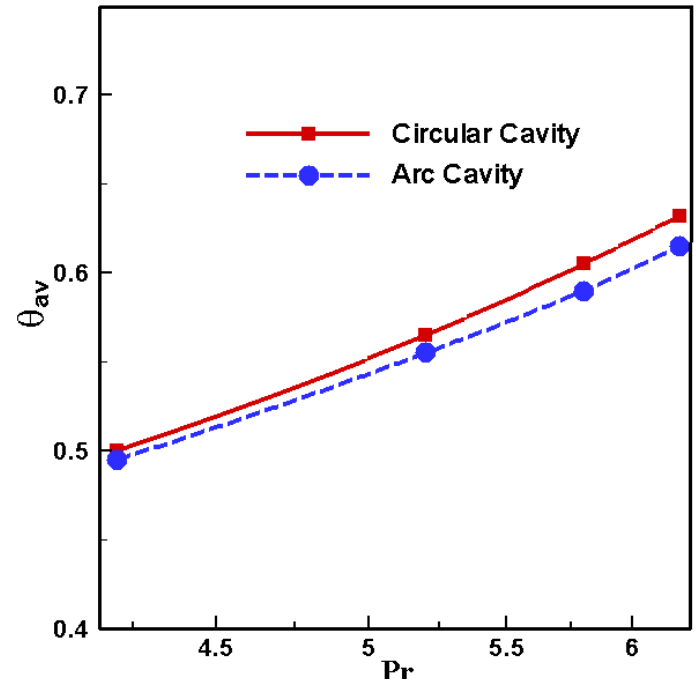

(a)

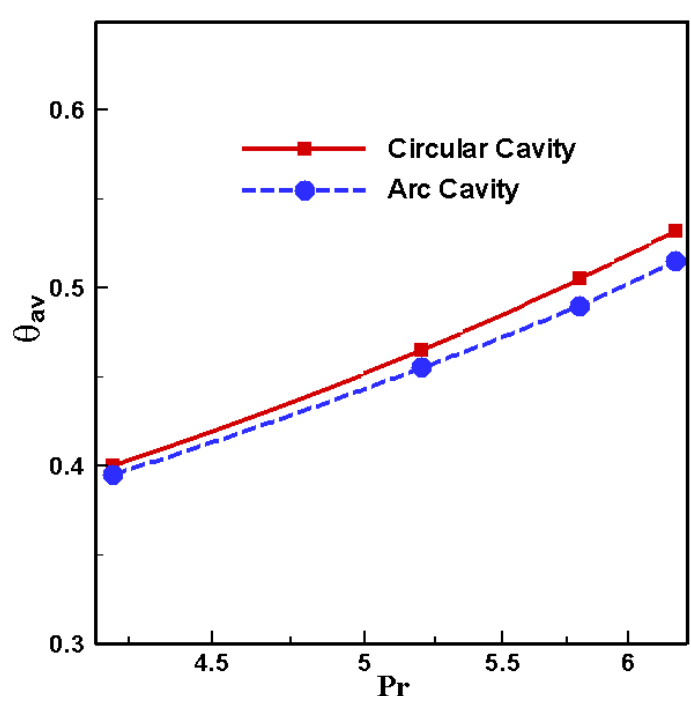

(b)

Figure 10: Mean temperature versus $\operatorname{Pr}$ using (a) water/Cu nanofluid and (b) water at $\mathrm{Ra}=10^{4}$

\subsection{Average velocity}

The average subdomain velocity of $2 \%$ concentrated water/Cu nanofluid and pure water in the circular as well as arc cavities against Rayleigh number at $\operatorname{Pr}=5.8$ is displayed in Figures 11(a)-(b) respectively. In this profile, the average velocity increases with the increasing value of Rayleigh number, $R a\left(=10^{3}, 10^{4}, 10^{5}\right.$ and $\left.10^{6}\right)$ for both the water/ $\mathrm{Cu}$ nanofluid and the clear water. This is due to the fact that more buoyancy force influences the fluid particles to move and get more velocity of heat transferring fluids.

Various effects of $\operatorname{Pr}(=4.2,5.2,5.8$ and 6.2) in the case of water/Cu nanofluid (solid volume fraction $2 \%)$ and base fluid on the subdomain mean velocity at $R a=10^{4}$ are demonstrated in Figures 12(a)-(b) respectively. For higher viscosity effect, the average velocity is predicted to decrease inside both the cavities because highly viscous fluid cannot move rapidly. Values of average velocity become higher for circular cavity than arc 
enclosure using both types of fluids. Apparently lower values of average velocity have been found for circular as well as arc-square cavities operated by $2 \%$ concentrated water/Cu nanofluid than clear water.

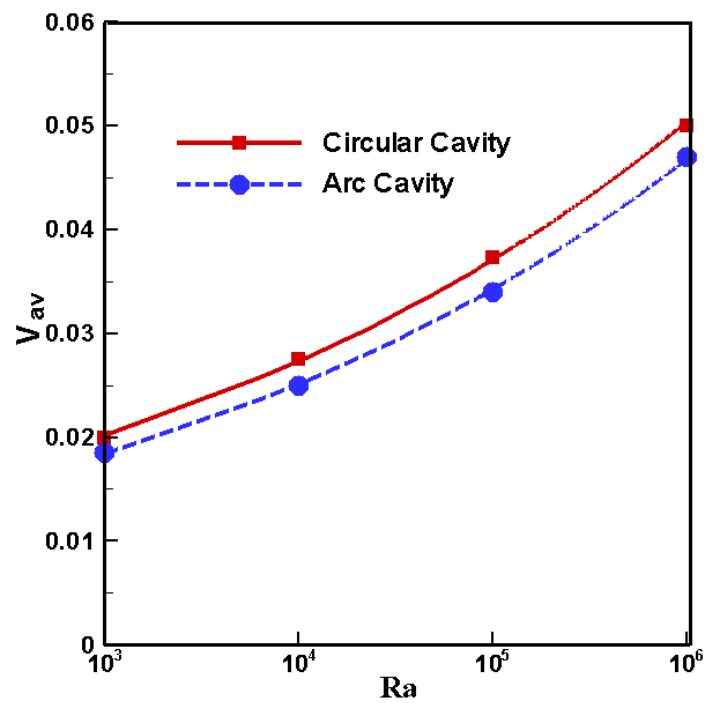

(a)

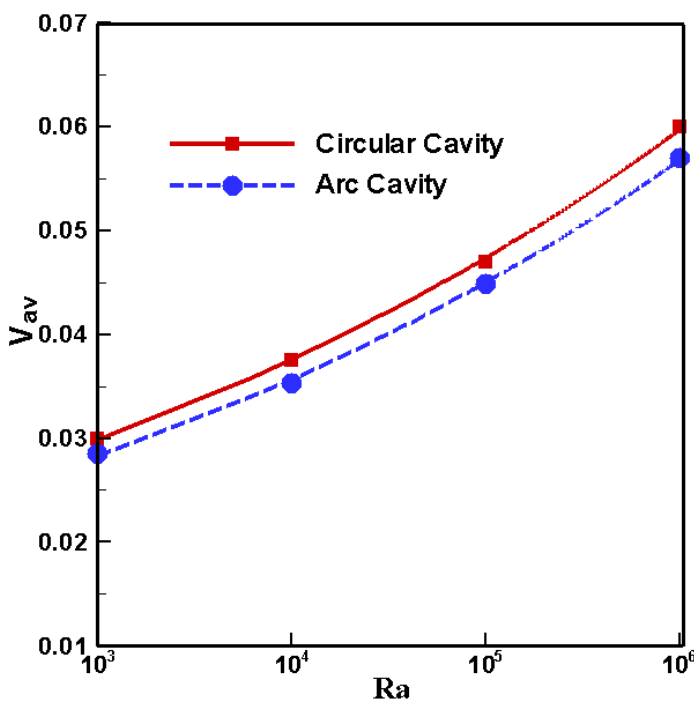

(b)

Figure 11: Mean velocity against $R a$ using (a) water/Cu nanofluid and (b) water at $\operatorname{Pr}=5.8$

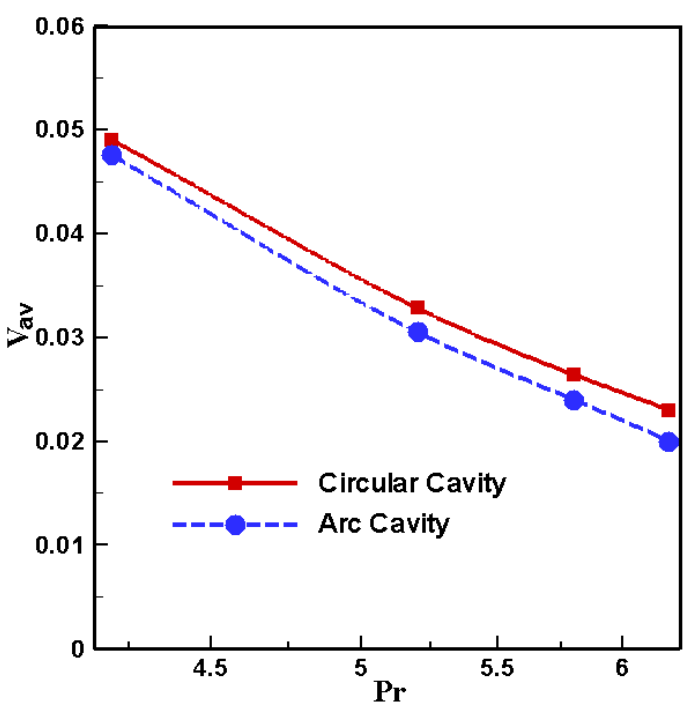

(a)

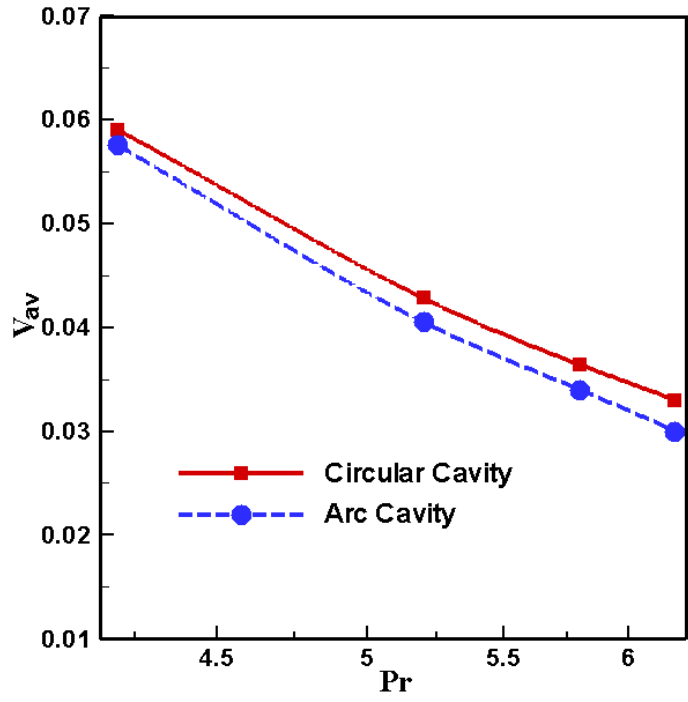

(b)

Figure 12: Mean velocity against $\operatorname{Pr}$ using (a) water/Cu nanofluid and (b) water at $R a=10^{4}$

\subsection{Correlation}

Two correlations have been developed among rate of heat transfer, Rayleigh number and Prandtl numb er using $2 \%$ concentrated water/ $\mathrm{Cu}$ nanofluid for circular as well as arc cavity with the range of $\operatorname{Pr}(4.2-6.2)$ and $R a$ $\left(10^{3}-10^{6}\right)$. The correlations are as follows:

For circular cavity: $N u=\left(1.099+0.3363^{*} P r\right)^{*}(R a)^{0.035}$, with correlation coefficient $R^{2}=99.9 \%$.

For arc-square cavity: $N u=\left(1.12+0.3371^{*} P r\right)^{*}(R a)^{0.032}$, with correlation coefficient $R^{2}=99.8 \%$. 


\section{Conclusion}

The prime objective of the current investigation is to compare the heat transfer phenomenon inside circular and arc enclosures using water/Cu nanofluid as well as pure water for the effect of buoyancy and viscous forces. From this research, it is found that the Rayleigh number and Prandtl number play significant role for fluid flow and heat temperature profiles. Higher heat transfer rate is observed for the enclosure filled with water/Cu nanofluid than the enclosure filled with pure water. The magnitude of mean velocity becomes superior for pure water than water/Cu nanofluid for both enclosures. About $2.7 \%$ higher heat transfer rate is obtained for circular cavity than that of arc cavity using water/Cu nanofluid at $\operatorname{Ra}=10^{4}$ and $\operatorname{Pr}=5.8$. It has been concluded that circular cavity is better to find higher heat transfer rate than arc cavity.

\section{References}

Abu-Nada, E., Masoud, Z., Oztop, H.F. and Campo, A. (2010): Effect of nanofluid variable properties on natural convection in enclosure, International Journal of Thermal Sciences, 49, 479-491, http://dx.doi.org/10.1016/j.ijthermalsci.2009.09.002.

Ahmed, K.F.U. and Nasrin, R. (2016): Numerical study of convective flow in a prismatic cavity using waterbased nanofluids, International Journal of Chemical Engineering and Analytical Science, 1 (2), 93-100.

Ahmed, K.F.U., Parvin S. and Chamkha, A.J. (2015): Numerical analysis based on heatline approach for natural convection flows within prismatic enclosures, International Journal of Energy and Technology, 7 (2), 19-29.

Chand, R., Rana, G. and Hussein, A.K. (2015): On the onset of thermal instability in a low Prandtl number nanofluid laver in a porous medium, Journal of Applied Fluid Mechanics, 8 (2), 265-272, http://dx.doi.org/10.18869/acadpub.jafm.67.221.22830.

Dechaumphai, P. (1999): Finite element method in engineering, 2nd edition, Chulalongkorn University Press, Bangkok.

Diaz, G. and Winston, R. (2008): Effect of surface radiation on natural convection in parabolic enclosure, Numerical Heat Transfer, Part A, 53, 891-906.

Ferdous, N., Islam, M.T. and Mamun, M.A.H. (2009): Natural convection and radiation in circular and arc cavity, Proceeding of International Conference on Mechanical Engineering, Dhaka, Bangladesh.

Hussein, A.K. and Hussain, S. (2016): Heatline visualization of natural convection heat transfer in an inclined wavy cavities filled with nanofluids and subjected to a discrete isoflux heating from its left sidewall, Alexandria Engineering Journal, 55, 169-186, http://dx.doi.org/10.1016/j.aej.2015.12.014.

Hussein, A.K. and Mustafa, A. (2017): Natural convection in fully open parallelogrammic cavity filled with $\mathrm{Cu}$ water nanofluid and heated locally from its bottom wall, Thermal Sciences and Engineering Progress, 1, 66-77.

Hussein, A.K., Bakier, M., Ben Hamida, M. and Sivasankaran, S. (2016): Magneto-hydrodynamic natural convection in an inclined T-shaped enclosure for different nanofluids and subjected to a uniform heat source, Alexandria Engineering Journal, 55, 2157-2169, http://dx.doi.org/10.1016/j.aej.2016.06.020.

Ismael, M.A. and Chamkha, A.J. (2015): Mixed convection in lid-driven trapezoidal cavities with an aiding or opposing side wall, Numerical Heat Transfer, Part A, 68 (3), 312-335.

Is mael, M.A., Al-Mayahi H.A. and Jawad I.N. (2014): Natural convection heat transfer in arc shape wall porous cavity filled with nanofluid, Basrah Journal for Engineering Sciences, 14 (2) 137-148.

Koca, A., Oztop, H.F. and Varol, Y. (2007): The effects of Prandtl number on natural convection in triangular enclosures with localized heating from below, International Communications in Heat and Mass Transfer, 34, 511-519.

Maxwell-Garnett, J.C. (1904): Colours in metal glasses and in metallic films, Philosophical Transactions of the Royal Society A, 203, 385-420, http://dx.doi.org/10.1098/rsta.1904.0024.

Mustafa, A.W. (2011): Natural convection in parabolic enclosures heated from below, Modern Applied Sciences, 5 (3), 213-220, http://dx.doi.org/10.5539/mas.v5n3p213.

Nasr, K.B., Chouikh, R., Kerkeni, C. and Guizani, A. (2006): Numerical study of the natural convection in cavity heated from the lower corner and cooled from the ceiling, Applied Thermal Engineering, 26, 772-775.

Nasrin, R. and Alim, M.A. (2013): Performance of nanofluids on heat transfer in a wavy solar collector, International Journal of Engineering Science and Technology, 5 (3), 58-77, http://dx.doi.org/10.4314/ijest.v5i3.6. 
Nasrin, R. and Alim, M.A. (2013): Free convective flow of nanofluid having two nanoparticles inside a complicated cavity, International Journal of Heat and Mass Transfer, 63, 191-198, http://dx.doi.org/10.1016/j.ijheat mass transfer.2013.03.068.

Nasrin, R. and Parvin, S. (2012): Investigation of buoyancy-driven flow and heat transfer in a trapezoidal cavity filled with water-Cu nanofluid, International Communications in Heat and Mass Transfer, 39 (1), $270-274$.

Pak, B.C. and Cho, Y. (1998): Hydrodynamic and heat transfer study of dispersed fluids with submicron metallic oxide particle, Experimental Heat Transfer, 11, 151-170.

Parvin, S., Ahmed, K.F.U., Alim, M.A. and Hossain, N.F. (2012): Heat transfer enhancement by nanofluid in a cavity containing a heated obstacle, International Journal of Mechanical and Material Engineering, 7 (2), 128135.

Parvin, S., Nasrin R. and Alim, M.A. (2014) Heat transfer performance of nanofluid in a complicated cavity due to Prandtl number variation, Procedia Engineering, 90, 377-382, http://dx.doi.org/10.1016/i.proeng.2014.11.865.

Parvin, S., Nasrin, R., Alim, M.A., Hossain, N.F. and Chamkha, A.J. (2012): Thermal conductivity variation on natural convection flow of water-alumina nanofluid in an annulus, International Journal of Heat and Mass Transfer, 55 (19-20), 5268-5274, http://dx.doi.org/10.1016/j.ijheatmasstransfer.2012.05.035.

Reddy, J.N. and Gartling, D.K. (1994): The finite element method in heat transfer and fluid dynamics, CRC Press, Incorporation, Boca Raton, Florida.

Sheikhzadeh, G.A., Arefmanesh, A., Kheirkhah, M.H. and Abdollahi, R. (2011): Natural convection of Cuwater nanofluid in a cavity with partially active side walls, European Journal of Mechanics B/Fluids, 30, 166176, http://dx.doi.org/10.1016/j.euromechflu.2010.10.003.

Taylor, C. and Hood, P. (1973): A numerical solution of the Navier-Stokes equations using Finite Element Technique, Computer and Fluids, 1, 73-89, http://dx.doi.org/10.1016/0045-7930(73)90027-3.

Triveni, M.K., Sen, D. and Panua, R.S. (2016): Numerical study of laminar natural convection in an arch enclosure filled with $\mathrm{Al}_{2} \mathrm{O}_{3}$-water based nanofluid, Journal of Applied Fluid Mechanics, 9 (4), 1927-1936, http://dx.doi.org/10.18869/acadpub.jafm.68.235.24798.

Triveni, M.K., Sen, D. and Panua, R.S. (2015): Convective heat transfer analysis in an arch enclosure, Front iers Heat and Mass Transfer, 6, 2, 1-6, http://dx.doi.org/10.5098/hmt.6.2.

Vahl Davis, D. (1983): Natural convection of air in a square cavity: A Bench Mark Numerical Solution, International Journal of Numerical Methods in Fluids, 3, 249-264, http://dx.doi.org/10.1002/fld.1650030305.

Vahl Davis, G. and Jones, I.P. (1983): Natural convection in a square cavity: A comparison exercise, International Journal of Numerical Methods in Fluids, 3, 227-248, http://dx.doi.org/10.1002/fld.1650030304.

Varol, Y., Koca, A. and Oztop, H.F. (2006): Natural convection in a triangle enclosure with flush mounted heater on the wall, International Communications in Heat and Mass Transfer, 33, 951-958, http://dx.doi.org/10.1016/i.icheat masstransfer.2006.05.003. 